\title{
Social science and indigenous ecological knowledge in Kakamega Forest, Western Kenya
}

\section{Oscar Kambona Ouma, Christoph Stadel \& Benjamin Okalo}

Keywords: indigenous ecological knowledge, scientific knowledge, conservation, Kakamega Forest, forest management regimes

\section{Abstract}

There is ample evidence in literature that indigenous knowledge, practices and beliefs often contribute to conservation and in some cases enhance local biodiversity. As a result there has been renewed interest in the use of indigenous knowledge, especially in forest management and conservation. Despite the renewed interest, incorporation of indigenous ecological knowledge in natural resource planning and management remains elusive. Using focus group discussions and in-depth individual interviews, the study gives an account of the beliefs, practices and norms that have been used for conservation by the adjacent community of Kakamega Forest over the years. The study also highlights the implications of successive forest management regimes on the use of resources and indigenous ecological knowledge. Results indicate that the local community applied various beliefs, practices and norms to regulate use of Kakamega Forest. However, the advent of forest management regimes has brought resource use restrictions which often neglect indigenous ecological knowledge. This study provides key intervention strategies important for enhancing the complementary functions of indigenous ecological knowledge and forest management objectives.

\section{Introduction}

Forests have traditionally been influenced by cultural belief systems and local management practices, and cultures in turn are based upon the ecological identity of the forest (Laird 1999). The practices and knowledge of indigenous societies are grounded in ethical, spiritual and cultural values that they impute to nature. There is ample evidence in the literature that indigenous knowledge, practices and beliefs often contribute to conserving, and in some cases enhancing, local biodiversity (e.g. Posey 1985; Gagdil et al. 1993). Indigenous ecological knowledge (IEK) and forest management practices have attracted greater attention for the insight they offer into forest ecology and for the potential they hold for increasing forest productivity and ecological resilience. Despite repeated calls for increased use of indigenous knowledge in conservation, integration of indigenous knowledge in natural resource planning and management remains undervalued. (Brokensha \& Vanek 1988; Redford \& Padoch 1992; Williams \& Baines 1993; DeWalt 1994; Dickson 1999; UNESCO-ICSU 1999; Belcher \& Kusters 2004). In Kenya the emphasis is on participative approaches to forest use, management and conservation (Government of Kenya 2007). The policy further recognizes that local people's knowledge should be tapped and incorporated into forest research and education while safeguarding their traditional interests and cultural practices. Despite the existence of the policy, a genuine complementarity with science-based
Profile

Protected area

Kakamega Forest

Mountain range

Nandi mountain range

Country

Kenya

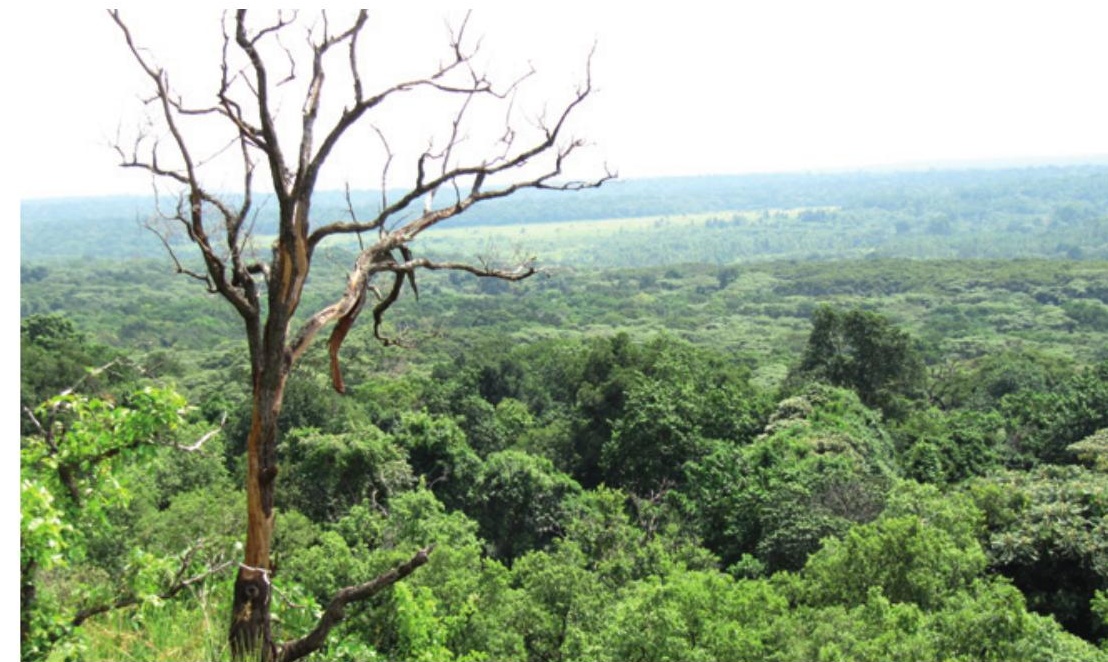

Figure 1 - View of Kakamega Forest canopy. (C) Stadel 2010

forest practices is yet to be fully realized. In Kakamega Forest national management has largely adopted a protectionist philosophy, which has consequently alienated most of the local community from use of forest resources. Since the local community no longer controls the use of resources, incorporating indigenous knowledge in the conservation and management of the Forest is a challenge. In order to encourage a comanagement of the Forest by national authorities and local communities, there is need for both locals and Forest management to cooperate in a climate of trust and mutual respect. This study suggests specific 


\begin{tabular}{|c|c|c|}
\hline $\begin{array}{l}\text { Etic approach } \\
\text { Review of literature \& com- } \\
\text { piliation of secondary data } \\
\text { Method: literature review }\end{array}$ & $\begin{array}{l}\text { Emic approach } \\
\text { Field research on the insiders' beliefs, } \\
\text { thoughts feelings and practices } \\
\text { Methods: focus group discussions and in }\end{array}$ & $\begin{array}{l}\text { Etic approach } \\
\text { Data analysis } \\
\text { Method: Krueger's framework analysis }\end{array}$ \\
\hline
\end{tabular}

Figure 2 - The integration of emic and etic research approaches in the study. Source: adapted from Krueger (1994)

intervention strategies that would enhance the complementarity of the two knowledge systems. Against this background the following research questions have been formulated: What beliefs and practices exist in Kakamega Forest region and how have they been used by the local community to manage and conserve the Forest over the years? What management regimes and strategies have existed in Kakamega Forest since the establishment of British rule in Kenya? What are the implications of forest management regimes and strategies on the use of indigenous ecological knowledge systems in the Kakamega Forest region?

\section{Conceptual framework}

Indigenous knowledge and resource use practice have been defined as a cumulative body of knowledge and beliefs handed down through generations by cultural exchanges about the relationship of human beings with one another and with their environment (Gadgil et al. 1993). According to Warren and Rajasekaran (1993), indigenous and traditional knowledge is specific to a given culture or society. Traditional ecological knowledge (TEK) focuses on local culture and interactions with their biotic and abiotic environment (Gadgil \& Berkes 1991; Nabhan 1997). These authors describe TEK as encompassing everything from a cursory awareness of natural environments to cultural norms for land management and resource use. In this study Indigenous Ecological Knowledge is used interchangeably with the term Traditional Ecological Knowledge. Indigenous ecological knowledge is acquired by local people through accumulation of formal and informal experiences and by an intimate understanding of the environment in a given cultural context.

Indigenous knowledge may contrast with the Western scientific and technical knowledge system generated by universities, research institutions and private firms. It is regarded as the basis for local decision making in agriculture, pastoralism, food preparation, health care, natural resource management, and a host of other activities in rural communities. In contrast to indigenous knowledge, which in many cases is passed on orally, scientific knowledge is transmitted through a rigid and agreed-upon set of scientific rules and methods, which qualifies it for a particular use (Fabricius et al. 2006). Moller et al. (2004) note that scientific knowledge is precise and easily measured in an objective and repeatable manner.

\section{Emic and etic concepts}

The emic and etic terminology (Figure 2) refers to basic approaches in cross-cultural studies involving the cultural settings of behaviour and the comparative analysis. Pike, an anthropological linguist, introduced the terms and suggested that the emic perspective emanates from studying behaviour from a cultural system. The etic perspective in turn relates to a behaviour with its roots outside a cultural system (Pike 1967). Harris (1968) modified Pike's definition. For him emic concepts refer to logical systems whose distinctions are perceived to be real and significant to the actors' beliefs, thoughts and attitudes. In contrast, the etic concept reflects the scientist's interpretation of the insider's thoughts and attitudes and analyses them with scientific methods. The two approaches are equally important, valuable and complimentary (Pike 1967).

\section{Adoption of the approach for the study}

In order to adopt the emic and etic concepts, this study uses the approach proposed by Berry (1999) which integrates the outsider's etic approach with an emic approach to arrive at an integrated etic-emic approach. As far as indigenous ecological knowledge in the Kakamega Forest region is concerned, the authors considered themselves as outsiders. The research procedure sets out by gathering relevant data through a literature review and by identifying specific knowledge gaps. In the second research procedure, the emic approach was used whereby the authors collected the insiders' beliefs, thoughts, feelings and practices by way of focus group discussions and in-depth individual interviews. In the last research procedure, the integrated etic-emic approach, an attempt was made to compare and assess the previous scientific findings with the collected data on indigenous ecological knowledge as shown in Figure 2. This was achieved by use of Krueger's framework analysis (Krueger 1994).

\section{Study area}

Kakamega Forest, illustrated in Figures 1 and 4, is a mid-altitude forest (1500-1700 $\mathrm{m}$ a. s. 1.) in western Kenya between $0^{\circ} 10^{\prime}$ and $0^{\circ} 21^{\prime}$ North and $34^{\circ} 47^{\prime}$ and $34^{\circ} 58^{\prime}$ East. Kakamega town is located on the western side of the Forest. To the south of the Forest, at a distance of about $50 \mathrm{~km}$, is the city of Kisumu on Lake Victoria. Adjacent to the Forest in the east is the Nandi escarpment which rises to an altitude of $2200 \mathrm{~m}$ a.s.l. The local community considers the region of Kakamega Forest and the adjacent Nandi escarpment a mountainous region. 
Cords and Tsingalia (1982), Kokwaro (1988), and Tsingalia (1988) describe Kakamega Forest as the eastern-most relic of the Guineo-Congolian type of rainforest that stretched from West Africa to Kenya and Uganda. The rainforest presents a unique biodiversity and habitat rarity, which makes it a sanctuary for a remarkable diversity of plants, birds, insects and other forms of animal life not found anywhere else in Kenya. The Forest is a source of several seasonal rivers that drain into Lake Victoria (Ogutu 1997, 31). Plant biodiversity is high, with 150 woody trees, shrubs and vines, 90 dicotyledonous herbs, 80 monocotyledonous herbs, of which 60 are orchids, and a further 60 species of ferns (Round-Turner 1994, 15).

Kakamega Forest is well known for its rich and endemic avifaunal composition. 350 bird species have been recorded in the Forest (Round-Turner 1994, 67). The Forest is also famous for its butterflies, of which 400 species have been identified (Round-Turner 1994, 67). The Forest supports a number of endemic primates. In view of its rich biodiversity Kakamega Forest is an important global conservation area.

\section{Methods of data collection and analysis}

\section{Focus group discussions}

According to Krueger and Casey (2014), a focus group discussion is about listening to concerned stakeholders and gathering information on a defined topic in an informal open meeting situation. The nonformal, relaxed and non-hierarchical free exchange of ideas allows researchers to determine the perceptions, feelings and manner of thinking of participants (Krueger 1994). Focus group discussions also fulfil a social support function by allowing the participants to share their stories, concerns and wishes with others and develop a sense of solidarity with people who are going through similar experiences or have similar circumstances (Peek \& Fothergrill 2009). In focus group discussion, the participants discuss specific issues without necessarily reaching a consensus or making a decision on which course of action to take.

\section{Conducting the focus group discussions}

We selected local community members residing near sections of the forest that have experienced degradation and within $3 \mathrm{~km}$ from the Forest boundary. Participants came from Isecheno, Kibiri, Ikuywa, Ileho, Mukulusi and Buyangu (Figure 3). In light of the criteria set out above and with the help of local elders, six people were chosen for focus group discussions and two for in-depth individual interviews from each of the six regions. All the respondents had attained a minimum of basic primary education and had various livelihood backgrounds, mainly of farming and small-scale business operations. The respondents were in the age range 45 to 70 years, with 55 percent males and 45 percent females $(n=36)$. The same ratio was maintained for those participating in in-depth indi-

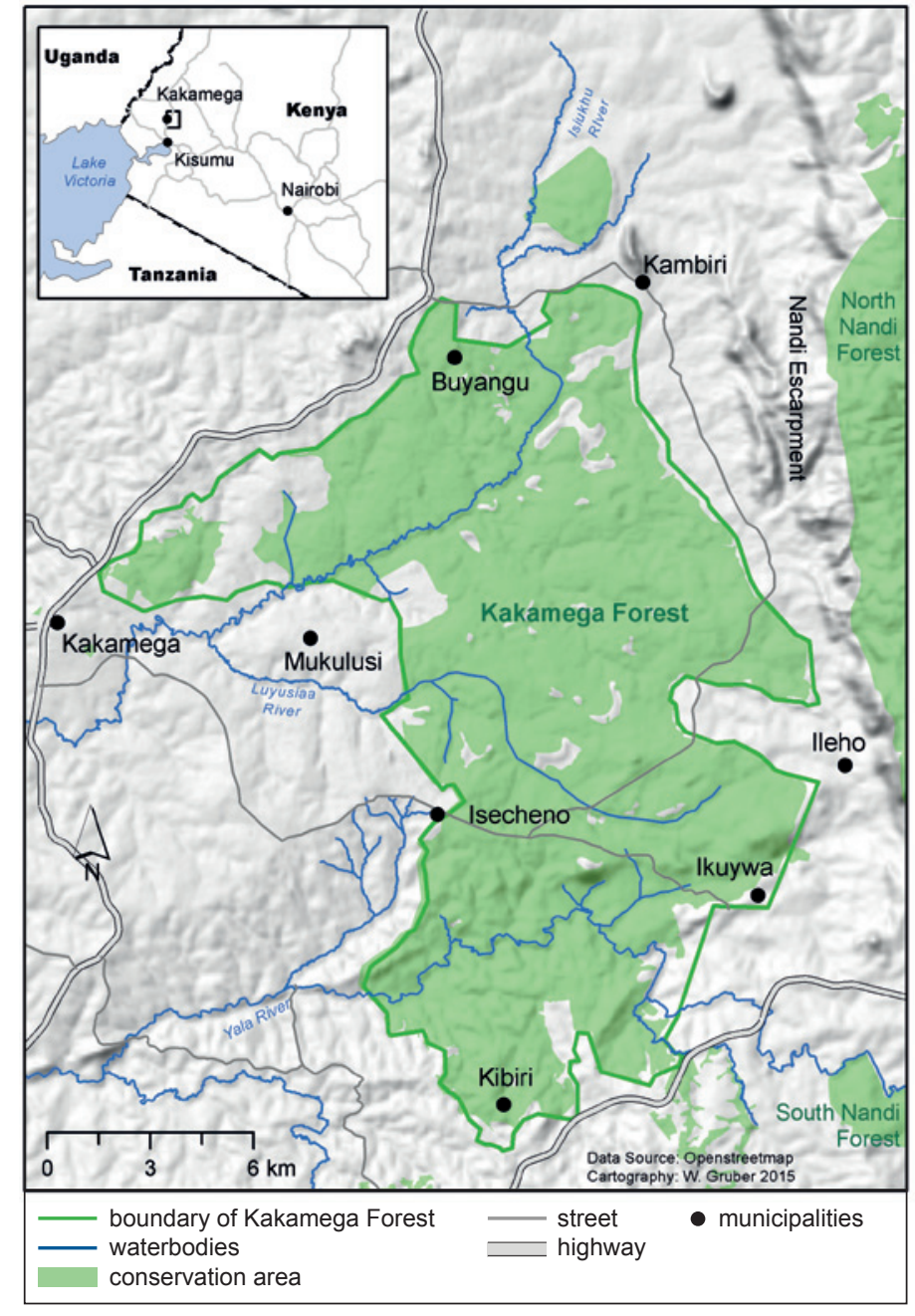

Figure 3 - Kakamega Forest and associated features. (C) Modified by $W$. Gruber (2015)

vidual interviews $(\mathrm{n}=12)$. Group discussion dynamics played a key role in the field research. This produced a range of responses from the participants, sometimes activating forgotten details. The discussions were held in the various homesteads of village headmen in the six study regions. The discussions were administered by one chair and two assistants who were taking notes and observing non-verbal communications. The chairs were selected from the local community and could speak and write in the local language (Isukha and Tiriki) and also in English. Each focus group discussion lasted for one to one hour and a half. After each focus group session, the researchers met with the chair and his assistants to review and compile the data before conducting the next focus group. In this way emerging topics in the previous discussions could be discussed, thus improving the overall quality of the discussions. Major topics addressed during focus group discussions and in-depth individual interviews are summarized in Table 1. 
Table 1 - Major topics addressed during the discussions and interviews. Source: authors (2009)

\begin{tabular}{|l|}
\hline Topics \\
\hline Firewood collection and charcoal production \\
Use of traditional vegetables, fruits, medicinal plants, grass, timber and tree trunks \\
Methods of hunting and fishing \\
Protection of water resources \\
\hline Circumcision ceremonies \\
Spiritual significance of the Forest \\
Cleansing ceremonies for societal deviants \\
Societal norms regulating forest use \\
\hline Wildlife-human conflict \\
Cultivation and pastoral activities in and around the Forest \\
\hline
\end{tabular}

\section{Data analysis}

Several approaches have been used in the analysis of focus group discussion data. These include: phenomenology (Van Manen 1990), grounded theory (Glasser \& Strauss 1967), content analysis (Krippendorf 1980) and narrative analysis (Reissman 1993). This study adopted Krueger's (1994) framework analysis but also incorporates some key stages of framework analysis described by Ritchie \& Spencer (1994). The advantage of the Krueger (1994) approach is that it follows a series of steps, which helps to handle large amount and complex qualitative data. Framework analysis as described by Ritchie \& Spencer (1994) is an analytical process which involves a number of distinct though bighly interconnected stages. The five key stages are: familiarization, identifying a thematic framework, indexing, charting, mapping and interpretation. The other distinctive aspect of framework analysis is that although it adheres to a thematic approach, it allows themes to develop both from the research questions and from the narratives of research participants.

The first analytic step was to get familiarized with the data. The aim of this process was to have a feel, get a sense and be immersed in the details of the focus group and in-depth individual interview. This was achieved by reading and assessing notes taken directly and those due to observations several times. Major themes began to emerge and were identified by written memos in the margin of the text as short phrases, ideas or concepts arising from the texts and categories began to develop. Three major themes emerged: livelihoods and forest conservation, cultural and religious practices, and human-wildlife conflict. At this stage descriptive statements were formed and an analysis carried out on the data. The third stage, indexing, comprised sifting the data, highlighting and sorting out quotes and making comparisons both within and between cases. The fourth stage, charting, involved lifting the quotes from their original context and re-arranging the field notes in a newly-developed appropriate thematic content. The last stage of the framework is mapping and interpreting. The study had to make sense of the individual quotes, but also be imaginative and analytical to discern the relationship between the individual responses and the links between the data as a whole. For example, guarding the forest with guns had to do with disregard of the traditional model where elders regulated resource use in the Forest and was therefore evidence of the Forest management's interference with an indigenous model of governance. Another interpretative aspect was taken when the respondents indicated use of warnings, such as the tree from where medicine was harvested being infested with snakes. The interpretative perspective implicit in this example is of reducing wasteful use of medicine from the tree since only those with real need for the resource would harvest the medicine. To increase validity of the results, the investigator took the following steps:

1. Topics and ideas that emerged in previous focus discussions were discussed in the subsequent group sessions.

2. At the conclusion of each session, the content of notes taken during the discussions were shared with at least one discussant from the group.

3. While interpreting the results, the field researchers re-examined the field notes and the memos. This ensured that the interpretations were within the cultural context of the local community.

4. A senior naturalist in the Forest was used as to chair the focus group discussions. At the end of each session, the naturalist, together with the two people taking notes, and the investigator met to compare notes and compile the data before the next focus interview. This greatly helped in identifying emerging ideas from the discussion and also remaining focused to the research aim.

\section{Results and discussions}

The information arising from the analysis of focus group discussions and in-depth individual interviews are reported and discussed in this section. The results and discussions are organized according to the themes that emerged during the data analysis.

\section{Rural livelihoods and forest conservation}

\section{Collection of firewood, fruit-bearing plants and charcoal production}

By assigning collection of firewood to elderly women who were more knowledgeable in firewood harvesting, the community ensured that firewood was not harvested from trees such as Antiaris toxicaria or any plant bearing edible fruit. Firewood was usually harvested from dead wood. The bark of $A$. toxicaria was traditionally used for making clothes. It was therefore believed that anyone using such trees for either firewood or charcoal burning would trigger a tragedy such as mental retardation or, worse still, be struck by lightning. The fruit-bearing plants were therefore spared from use as firewood and instead left to mature to be used as food by the community. Not every part of the Forest used to be made accessible for firewood collection. Elders within the community designated specific areas for firewood collection, circumcision 
ceremonies, cleansing rituals and water catchment points. Since firewood was the main source of energy for cooking, it was used sparingly. Households conserved the firewood remains by mixing it with wet cow dung. This ensured that the firewood could be used again, reducing the quantity extracted from the Forest. With the arrival of Asian and European settlers in the Forest in the early 1920s the conservation practice became largely ignored. The type of food that formed the settlers' diet required more charcoal than firewood for cooking. With the introduction of charcoal production, the community had an alternative source of energy. However, they still upheld the practice of using only fallen trees for charcoal production. The traditional methods used for harvesting trunks and grass were generally less harmful to the forest ecology. For instance, several people would gather around a tree and use their manpower to pull out a trunk. Similarly, grass was harvested by hand. Social customs, such as marriage status, also restricted resource use from the Forest. Only married men who had at least two children were allowed to harvest grass. Since the resource extraction methods were tedious and labour intensive, wasteful and non-sustainable resource use practices were minimized.

\section{Conservation of trees and birds in the Forest}

Traditional beliefs and warnings were often used by the community as a way of conserving trees and animals in the Forest. For instance, people extracting medicine from the munyama tree (Trichilia emetica) were told that the tree was inhabited by snakes. This made harvesting a cautious and delicate process and only those who had real need for the medicine dared to visit the snake-infested tree. In general, the practice of herbal medicine was restricted to the elderly (at least 40 years), married people and those who had the traditional knowledge handed to them by their parents. Collection of medicinal plants was usually, but not exclusively, done by men. It was believed that those who violated these norms would never get married. Most of the medicinal plants were harvested during the day. However, some medicine, especially from the murembe tree (Red poker, Erithrina abysinica) (Figure 4) was harvested at night by naked collectors. The tree was considered sacred as dead people were buried near it. As such, the tree and the vegetation in the surrounding area remained relatively undisturbed. The locals also believed that the use of certain trees, such as mukango (Pouteria altissima) or mulundu (A. toxicaria) for house construction would give the owner of the house bad dreams. These beliefs and practices formed a strong traditional norm within the community which regulated the sustainable use of trees and medicinal plants.

The community also held various beliefs about birds. For example, killing a pied wagtail (Motacilla aguimp vidua) would make the house of the hunter burn; the cries of certain birds signified death to the hearer while other cries were an indicator of the onset of

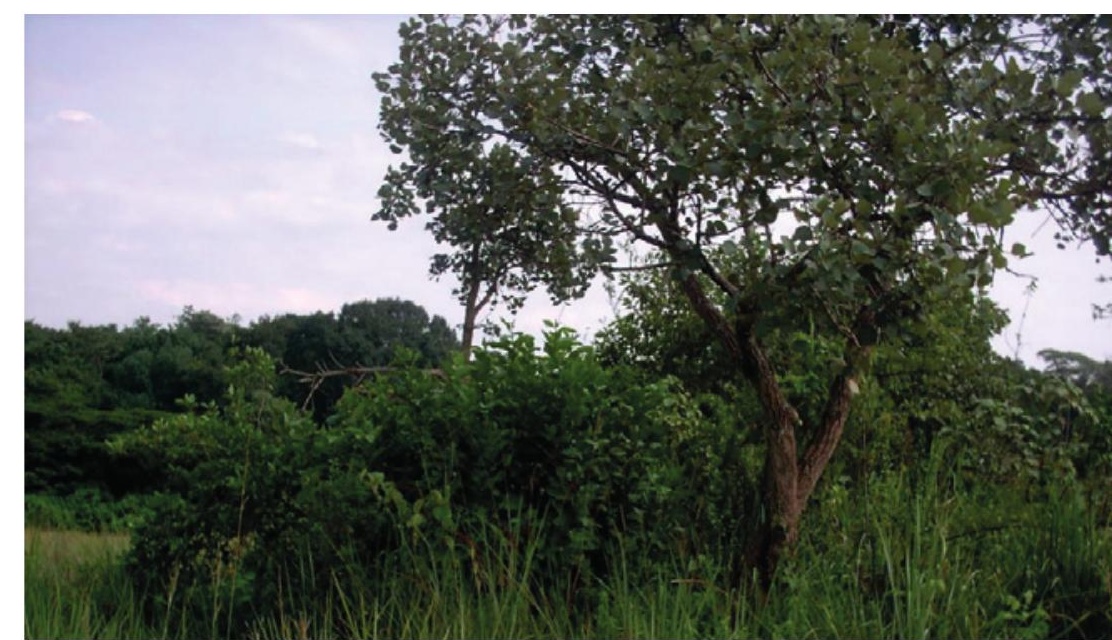

Figure 4 - Murembe tree (Erithrina abysinica). (C) Kambona (2009)

rainy seasons. The long-crested eagle (Lophaetus occipitalis) was believed to have some kind of wisdom as it could foretell where one's spouse would come from. As a result of the traditional beliefs, the community members regarded the birds as important social, cultural and religious assets that were not supposed to be hunted.

Methods of hunting, fishing and protecting the water resources

Several strategies were put in place to regulate hunting. Only known individuals within the community were allowed to hunt and specific areas of the forest were set aside as hunting territories. Hunting was done selectively and only on mature animals. If a young or pregnant animal was accidentally captured during hunting, it was released. The community permitted only elderly people (at least 40 years old) to fish. The methods for fishing used fishing lines and hooks, baskets as traps, as well as spearing fish. Here again only mature fish were harvested. The community attempted to conserve the water sources in the Forest by planting several trees, such as the musiema tree (Sysygium quinensis), the mukumu tree (Ficus thorningii) and the lukbuvu plant (Draceana fragrause) around water bodies. Musiema and mukumu trees were believed to store water and therefore were not supposed to be cut down. The integrity and sacredness of conserving water resources contributed to the rich biodiversity and to the abundance of water in the Kakamega Forest region.

\section{Cultural practices}

Circumcision, especially in the Luyha sub-tribe of Tiriki, was performed inside the Forest. The Forest provided a safe sanctuary where the boys were secluded from the rest of society while they learnt the traditional ways and values of the forest. The Forest provided access to sufficient resources, such as water and medicinal plants, which were used for healing the circumcised. As a result the local people attached a lot 
of importance to the conservation of the Forest and especially the circumcision sites.

In some regions, such as Ileo (Figure 3), elders placed a stone in the Forest as a site for their prayers. Only the elders were allowed to this site. Another designated area within the Forest considered as sacred was the Lirhanda Hill. The Hill is still being used for prayers to date. In this way sacred sites have experienced less ecological disturbance compared to nonsacred sites.

A study conducted by Haupt (2000) indicates that ancestral spirits in the Kakamega Forest region act as mediators between their living relatives and the supernatural powers. Some of the local people give examples of a spiritual link to their ancestors through certain tree species, the most common being the murembe tree, (E. abysinica) and the mukumu tree (F. thoningii). For example, local people believe that the spirits of their ancestors reside in the mukumu tree. The community pray there for societal deviants, such as those who have committed incest, murder or are under a curse. The spirits residing in the tree could also be consulted whenever the community experienced adverse weather conditions such as drought. The planting of and care for the mukumu tree is a privilege for the males in the community. The females are expected to be married out of the area and would not be available to take care of the tree as it grows. The tree remained protected because of the reverence attached to it.

\section{Human-wildlife conflicts}

Human-wildlife conflicts are a common occurrence in Kenya's protected areas. In Kakamega Forest the conflicts have involved wildlife feeding on cultivated crops such as beans, maize and potatoes. Mostly primates, particularly monkeys and baboons, are involved in conflicts with human beings. However, the high human population around the forest has increased agricultural and resource use pressure in the Forest and wildlife habitats inside the Forest have been affected. In the northern part of the Forest, human-wildlife conflicts have become so intense that some local community members have had to relocate their homes away from the Forest. Others have abandoned their farms and rented farms away from the Forest (Kambona \& Stadel 2014).

In the past, wild animals inside the Forest had enough food and experienced minimal interference from human beings. Besides, the crops planted in the past, such as millet and sorghum, were not food sources for the wild animals. Animals staying deep in the forest rarely encountered humans and incidences of wildlife-human conflicts were minimal. Whenever conflicts did occur, the local community used various strategies to control the animals, for example, mimicking sounds of the targeted animals to scare them away; lighting fires to repel the animals with the smoke; hanging scarecrows and skins of the animals in strategic positions to repel invading animals. The animals were also kept away from cultivated crops with the sounds of drums, bells and trumpets. These strategies rarely injured or killed animals thus promoting conservation. In more recent times, with a deeper and more intensive penetration of humans in the forest, humanwildlife conflicts have become a serious issue.

\section{Management aspects in Kakamega Forest}

Kakamega Forest was originally managed by the local people through their village elders until 1918 when they had to yield to governmental control (Mitchell 2004) amid great local resentment. According to Kamugisha et al. (1997), the forest was under the management of elders who made decisions on which trees to use for construction. Opole (1991) revealed the existence of seven kavunyondos or communal forests that were jointly owned by the Tiriki community. The community selected individual members to manage and regulate the use of the forest. He notes that these leaders still exercised their authority until 1991 although their powers had been greatly reduced by the Forest Department. The discovery of gold in the Forest in 1923 prompted the colonial government to declare the forest a County Council Forest. In 1933 it was gazetted as a Government Forest Reserve (Round-Turner 1994, 9) and managed as a trust land forest. This meant that although the forest would remain the property of the local people, the government would manage it on their behalf. A few customary rights of the people to the forest were reinstated by special rules issued in 1959 and 1964 allowing local residents the right to use the forest for grazing, cultivation and collection of firewood. The area remained a County Council Forest until 1963, when the Forest came under the administration of the Forest Department (Forest Department, undated).

In 1967, in an attempt to regulate human use of Kakamega Forest, the Government established 140 ha and 510 hectares of the Forest as the Isecheno and the Yala Nature Reserves respectively (Round-Turner 1994, 10). The northern part of about 4000 ha in Buyangu was considered a relatively pristine ecosystem and a genuine ecological representative of the Kakamega Forest. In 1985 the government declared it the Kakamega National Forest Reserve, together with the adjacent Kisere Forest (about 500 ha) (KIFCON 1992, 1). It is managed by Kenya Wildlife Service (KWS) as a national reserve. The southern part of the Forest (about 18000 ha) is managed by the Kenya Forest Service. As indicated in Figure 3, the Isiukhu River forms the boundary between the two forest management regimes. The two management bodies generally pursue a top-down approach in their strategies, focusing on law enforcement, licensing of permitted extraction of forest produce, control of animals, maintenance of trails and forest roads, as well as raising public awareness on conservation and tourism development. In recent years the Forest Department in the southern part of the Forest has assigned specific areas inside the forest to the local people for crop cultivation. In this 
land use scheme, the people tend their crops and the tree seedlings on the same piece of forest land until the trees become too large and dense for continuation of agricultural use. The local people are then allocated another piece of land where the same practice is repeated. However, this system was stopped in 2003 because of deforestation and charcoal burning by the local community.

Kakamega Forest management and indigenous ecological knowledge

The establishment of the British colonial rule in 1895 is by and large associated with the creation of national parks and reserves in Kenya. In Kakamega Forest this brought with it a highly regulated system of forest use, which greatly reduced the use and control of the forest resources by the community. The people now had to pay fees to use the resources. The colonial authority begun to exploit forest products like wood for export and large forest areas were cleared for cash crop cultivation (i.e. maize and tea) (Ogutu 1997, 40). The construction of the Kenya-Uganda railway and the introduction of wood-burning locomotives increased the demand for wood. This led to the establishment of the first eucalyptus tree plantations in the Forest (Kokwaro 1988, 473). The eucalyptus is not native to Kenya and paved the way for the introduction of other commercially viable exotic tree species (such as pine and cypress) in the Forest at the expense of native species. With the establishment of the Forest as a protected area, indigenous ecological knowledge has gradually been replaced by sciencebased approaches. For example, the Luyha sub-tribe of Tiriki appointed a group of community members known as Nandwa whose primarily duty was to oversee the use of Forest resources. Over the years their role has been replaced by forest guards. Community members complain that the guards are not sensitive to their resource use needs. One person from the community expressed his dissatisfaction with the Forest Management as follows:

"The idea of guarding the Forest Reserve with guns is not feasible" (Community member from Buyangu during focus group discussion, 8 April 2008).

Zoning, which is one of the strategies adopted by the Forest Management, has resulted in a restrictive use of forest resources. For example, the use of wild honey, firewood, medicinal plants and grazing lands has been curtailed especially in the northern part of the Forest. Zoning has also greatly disrupted access to and use of sacred sites by the local community. For example, an open glade locally known as Mananyenzo, is no longer accessible to the elders for prayers. In ancient times the local community used to kill some colobus monkeys for use in traditional festivals. However, this has been curtailed by the management. A person from the Community summed up the dilemma:

"The local community has no right over the use of forest resources and most of the resources are either obtained illegally or fees are charged for them" (Community member from Buyangu during focus group discussion, 8 April 2008).

Since the northern part is a forest reserve, most traditional approaches to forest management have been abolished by the Kenya Wildlife Service - in the words of one community member:

"Establishment of Kenya Wildlife Service in the northern part of the Forest has brought poverty to the region" (Community member from Buyangu during focus group discussion, 8 April 2008).

Massive and exploitative commercial logging activities which have been encouraged by the Management in the past have greatly reduced the area stocked with indigenous trees. This has also gradually eroded the beliefs and practices that were associated with them (e.g. murembe, mukumu and munyama).

Key intervention strategies towards complementarity of the two knowledge systems

As already noted for the Kakamega Forest region, indigenous ecological knowledge and forest management objectives have not adequately complemented each other. Furthermore, indigenous ecological knowledge in the region, as in many other parts of the world, is threatened with being ignored or lost in the process of relying solely on modern science and technology. In addition to this the changing family structure does not provide an enabling environment for the transmission of indigenous ecological knowledge. Regular assessment, updating and compilation of indigenous ecological knowledge as a pre-requisite for its use in the management of the Forest is therefore worth considering. Against this background the authors have suggested the following strategies for a more successful, cooperative and complementary model of knowledge system and resource management principles:

\section{Micro-approach to complementarity of the knowledge systems}

From the prior discussions there is no doubt that a substantial body of indigenous ecological knowledge about Kakamega forest ecosystem exists. However, adopting a macro-approach to the complementarity of the two knowledge systems is neither practical nor synergistic. Instead a micro-approach would yield better results given that each species is ecologically, culturally and socially unique. For example, the mukumu tree is of religious, cultural and social significance to the Isukha people. To improve the use and management of the tree, specific indigenous ecological knowledge and scientific knowledge about the tree should be shared between the local people and the Forest Management.

\section{Sharing managerial rights and authority}

The existing managerial model of Kakamega Forest (especially in the northern part) sees the local community more as a resource spectator than an actor. Cur- 
rently the scenario is based on power arrangements highly in favour of the government Forest Management. For the local people to take on an active role and responsibility in resource management, the Forest Management should cede some authority to the locals. This has to be done on the basis of sound policy and legal frameworks and in a climate of genuine trust and cooperation. Only when the local people have some power over the use of resources can they apply their indigenous knowledge to its full potential.

\section{Community consultative panels}

The results from this study indicate that there is some distrust and animosity between the local people and the government Forest Management. The Management could greatly reduce this by incorporating indigenous ecological knowledge into their management plans and giving a voice to local people, e. g. through establishing community consultative panels around the Forest. The panels would be composed of local people and forest management personnel. Their aim would be to oversee, consult and advise on the complementarity of the two knowledge systems in the Forest. For example, the complementary role of monitoring use of forest resources would be done jointly by the forest wardens and the traditional Nandwa model discussed above.

\section{Forest Open Days}

To encourage collaborative and transparent approaches of the two knowledge systems, the Forest management, in consultation with the local community and other stakeholders, should organize Forest Open Days each year. During a Forest Open Day, forest stakeholders would get together to learn from each other without any hierarchical constraint. All stakeholders, including the local people, would be given access to the protected area in order to learn about, experience and appreciate the Forest. At the same time, the Forest management and other stakeholders would be expected to learn from and appreciate the various beliefs, practices and norms that regulate conservation and traditional use of forest resources.

\section{Conclusion}

Kakamega Tropical Rainforest region is a repository of indigenous ecological knowledge which the local communities have used over the years to maintain a balance between their need for resources and the conservation of the Forest. The knowledge ranges from regulating livelihoods and conservation of the forest, through culture and religious practices to controlling human-wildlife conflicts. The introduction of forest management objectives and policies by the colonial and successive governments has severely interfered with the local community's control and use of forest resources. This in turn has seriously inhibited the local community's use of indigenous ecological knowledge.
The prevailing management conditions have not supported the complementary functioning of the indigenous ecological knowledge system with the forest management objectives. This study has attempted to move forward the frontier of knowledge in forest conservation and management by coming up with key intervention strategies for bridging the gap between the two knowledge systems. The challenge now remains with the implementation of the strategies. However, the use of these strategies alone may not ensure sustainable conservation of Kakamega Forest. Conservation of the Forest is dependent on many factors. The World Bank (2007) in its strategic environmental assessment on Kenya's Forest Act 2005 identifies attitude change, staff motivation, poverty among the communities around the Forest and inadequate governance structures and institutions as a great influence on conservation in Kenya's forests. Two management regimes (Kenya Forest Service and Kenya Wildlife Service), each with a different mandate, manage different parts of Kakamega Forest. This has brought conflicting roles which slow the pace of implementation for policies on forest conservation and management. The prevailing poverty among communities adjacent to the forest is another factor that requires poverty alleviation policies and strategies for sustainable forest conservation.

Since the Forest Act 2005 allows for mandatory rehabilitation of degraded forests through temporary takeover as provisional forests, the adjacent Forest communities could identify degraded forest belts, which they could take over and conserve using indigenous ecological knowledge. The Act also provides for joint biodiversity conservation between forest management and adjacent forest communities. As Kakamega Forest already has community-based organizations (for example, Kakamega Environmental Education Programme), participatory forest management could be improved along the Rumuruti Forest management model, since that Forest has faced challenges similar to those in Kakamega Forest in recent years. Forest rehabilitation, joint forest patrols and livelihood improvement programmes have been achieved through this model. Like internationally recognized conservation areas elsewhere, Kakamega Forest and the surrounding region represent considerable biodiversity and cultural significance and would warrant consideration as a UNESCO biosphere reserve. This would ensure a move towards a balance between the ecological, socioeconomic and cultural aspects of the Forest. Such a balance would enhance the complementarity between scientific methods of forest conservation and indigenous ecological knowledge.

\section{References}

Becker, C.D. \& R. Leon 2000. Indigenous institutions and forest condition: lessons from the Yuracare. In: Gibson, C., M. McKean \& E. Ostrom (eds.), Peo- 
ple and forests: communities, institutions, and the governance: 163-191. Massachusetts.

Belcher, B. \& K. Kusters 2004. Non-timber forest product commercialization: development and conservation lessons. In: Kusters, K. \& B. Belcher (eds.), Forest products, livelihoods and conservation: case studies of nontimber forest product systems: 1-22. Bogor.

Berry, J.W. 1999. Emics and etics: A symbiotic conception. Culture and Psychology 5: 165-171.

Brokensha, D. \& E. Vanek 1988. Enhancing environmental resource management in developing nations through improved attitudes towards indigenous agricultural knowledge systems. Science, Technology and Human Values 13: 10-101.

Cords, M. \& H.M. Tsingalia 1982. Harmful exploitation of indigenous forest in Kakamega. Unpublished report.

Cundill, G., C. Fabricius \& N. Marti 2005. Foghorns to the future: using knowledge and transdisciplinarity to navigate complex systems. Ecology and Society 10(2): 8 .

DeWalt, B. 1994. Using indigenous knowledge to improve agricultural and natural resource management. Human Organization 53(2): 123-131.

Dickson, D. 1999. ICSU seeks to classify "traditional knowledge." Nature 401: 631.

du Toit, J.T., B.H. Walker \& B.M. Campbell 2004. Conserving tropical nature: current challenges for ecologists. Trends in Ecology and Evolution 19(1): 12-17.

Fabricius, C., R.J. Scholes \& G. Cundill 2006. Mobilising knowledge for ecosystem management. In: Reid, W.V., F. Berkes, T.J. Wilbanks \& D. Capistrano (eds.), Bridging Scales and Knowledge Systems. Concepts and Applications in Ecosystem Assessment Chapter 9. Washington.

Forest Department undated. Kakamega Forest. Unpublished paper.

Gadgil, M. \& F. Berkes, 1991. Traditional resources management systems. Resource management and Optimization 8(3-4): 127-141.

Gadgil, M., F. Berkes \& C. Folke 1993. Indigenous Knowledge for Biodiversity Conservation. Ambio 22: 151-156.

Gadgil, M., P. Olsson, F. Berkes \& C. Folke 2003. Exploring the role of local ecological knowledge in ecosystem management: three case studies. In: Berkes, F., J. Codling \& C. Folke (eds.), Navigating social-ecological systems: building resilience for complexity and change: 189209. Cambridge.

Glaser, B.G., A.L. Strauss \& E. Strutzel 1968. Discovery of grounded theory: Strategies for qualitative research. Nursing Research 17(4): 364.

Government of Kenya 2007. Forest policy Sessional paper number 1. Nairobi.

Haupt, M. 2000. Traditional use of and reliance on the forest among the Lubya people with special regard to the traditional medical system and the use of medicinal plants in Kakamega Forest, western Kenya. Unpublished PhD Thesis. University of Trier, Germany.

Harris, M. 1968. The rise of anthropological theory. New York.
Kambona, O.O. \& C. Stadel 2014. Ecotourism and rural livelihoods-linkages and interactions for the Kakamega Forest region. In: Schmitz, M.F. (ed.), Tourism and Natural Protected Areas: 79-90. Boston.

Kamugisha, J.R., Z.A. Ogutu \& M. Stahl 1997. Parks and people - conservation and livelihoods at the crossroads. Four case studies. Regional Soil Conservation Unit / Swedish International Development Cooperation Agency. Technical Report No. 17. Nairobi.

Kenya Indigenous Forest Conservation (KIFCON) 1992. Natural Forest Management and Conservation. The Kakamega Forest Sight Survey, Working Paper No. 6. Nairobi.

Kenya Indigenous Forest Conservation (KIFCON) 1994. Kakamega Forest. The official guide. Nairobi.

Kokwaro, J.O. 1988. Conservation status of the Kakamega Forest in Kenya: the eastern most relic of the equatorial rainforest of Africa. Monograph of Botany at the Missouri Botanical Gardens 25: 471-489.

Krippendorff, K. 1980. Content Analysis: An Introduction to its Methodology. London.

Krueger, R.A. \& M.A. Casey 2014. Focus Groups: A Practical Guide for Applied Research. California.

Laird, S. 1999. Forests, culture and conservation. In: Posey, D.A. (ed.), Cultural and Spiritual V alues of Biodiversity: 347-362. London.

Moller, H.F., F. Berkes, L. O’Brian \& M. Kislalioglu 2004. Combining science and traditional ecological knowledge: monitoring populations for co-management. Ecology and Society 9(3): 2.

Nabhan, G.P. 1997. Cultures of habitat: On nature, culture, and story. Washington.

Ogutu, Z.A. 1997. Regional Soil Conservation Unit/ SIDA-Technical Report No.17. In: Kamugisha, J.R., Z.A. Ogutu \& M. Stahl (eds.), Parks and people - conservation and livelihoods at the crossroads - four case histories: 31-45. Nairobi.

Olsson, P. \& C. Folke 2001. Local ecological knowledge and institutional dynamics for ecosystem management: a study of Lake Racken Watershed, Sweden. Ecosystems 4(2): 85-104.

Opole, M. 1991. User trends and attitudes to management of the Kakamega Forest reserve. Kenya Indigenous Forest Conservation Programme, Nairobi.

Peek, L. \& A. Fothergill 2009. Using focus groups: Lessons from studying daycare centres, 9/11, and Hurricane Katrina. Qualitative Research 9(1): 31-59.

Pike, K. 1967. Language in relation to a unified theory of the structure of human behavior. The Hague.

Redford, K.H. \& C. Padoch 1992. Conservation of neotropical forests: working from traditional resource use. New York.

Riessman, C.K. 1993. Narrative analysis. California.

Ritchie, J. \& L. Spencer 1994. Qualitative data analysis for applied policy research. In: Bryman, A. \& R.G. Burgess (eds.), Analysing Qualitative Data: 173-194. London.

Round-Turner, D. 1994. Kakamega Forest, the official guide. Nairobi. 
Ruddle, K. \& R.E. Johannes 1989. Traditional Marine Resource Management in the Pacific Basin: An Anthology. Jakarta.

Tsingalia, M.H. 1988. Animals and the Regeneration of an African Rainforest Tree. Unpublished Ph.D. Thesis. University of California, Berkeley.

United Nations Educational, Scientific and Cultural Organization (UNESCO) - International Council of Scientific Unions (ICSU), 1999. Declaration on science and the use of scientific knowledge. Paper presented in the World Conference on Science for the Twentyfirst Century, 26 ${ }^{\text {th }}$ June-1 $1^{\text {st }}$ July 1999. Budapest. Available at http://www.unesco.org/science/wcs/eng/ overview.htm (accessed on 17/07/2015)

Van Manen, M. 1990. Researching Lived Experience: Human Science for an Action Sensitive Pedagogy. Ontario.

Warren, D.M. \& B. Rajasekaran 1993. Putting local knowledge to good use. International Agricultural Development 13(4): 8-10.

Williams, N.M. \& G. Baines 1993. Traditional ecological knowledge: wisdom for sustainable development. Canberra.

World Bank 2007. Strategic environmental assessment of the Kenya Forests Act 2005. Washington, DC. Available at http://documents.worldbank.org/curated/ en/2007/01/16569567/strategic-environmentalassessment-kenya-forests-act-2005 (accessed on 26/08/2015)

\section{Authors}

\section{Oscar Kambona Ouma}

was born in the Lake Victoria region, western Kenya. He worked for nine years as a senior lecturer in project and environmental management at the Kenya School of Governance, Nairobi. In 2006 he took up a position at Maseno University as a senior lecturer in ecotourism, sustainable tourism and protected areas. He has done research in Kakamega Forest, Maasai Mara National Game Reserve and Berchtesgaden $\mathrm{Na}$ tional Park. His areas of research include indigenous ecological knowledge, ecological footprint, ecotourism, interactions of local communities with protected areas. He holds a Ph.D. in Natural Science - Geography from the University of Salzburg, Austria. Contact: kaudo2015@gmail.com

\section{Christoph Stadel}

holds a Ph. D degree in Geography, History and French literature from the University of Fribourg, Switzerland. For 24 years he was Professor of Geography at Brandon University, Canada. In 1992 he was appointed as an Ordinarius for Geography at the University of Salzburg and became a Professor Emeritus in 2004. He is also an Adjunct Professor at the Institute of Natural Resources of the University of Manitoba, Canada. His areas of research include cultural geography, development studies, comparative mountain studies, the tropical Andes, the Canadian Prairies, and Kenya. E-mail: christoph.stadel@sbg.ac.at

\section{Benjamin Okalo}

works as a senior naturalist in Kakamega Forest. He has extensive scientific and indigenous knowledge in plant and animal ecology spanning over 20 years. He has been involved in several research activities in the forest. Under his leadership Kakamega Environmental Education Programme (KEEP), a communitybased organization, has initiated pro-forest conservation programmes for pupils, students, tourists and entrepreneurs. E-mail: admin@keep-kakamega.or.ke 